\title{
ACTIVITIES AND TRENDS IN THE RESEARCH DIVISION OF PSYCHOLOGY OF PHYSICAL EDUCATION IN 1975-1976
}

\author{
Hisashi Wada \\ Osaka Univ.
}

The researches in this division were mainly presented at National Convention of Japanese Society of Physical Education, National Convention of Japanese Society of Sport Psychology, and also published in Japanese Journal of Physical Education (the former "Research Journal of Physical Education") and in the university bulletins.

The number of research papers on psychology presented at National Convention of Japanese Society of Physical Education were 54 in 1975, and 30 in 1976. Subjects treated in those papers were classified into ten research areas and the number of papers on each area are shown in Table 1.

Table 1 Number of the papers presented at National Convention of Japanese Society of Physical Education

\begin{tabular}{l|c|c}
\hline \multicolumn{1}{c|}{ Research Areas } & 26th meeting (1975) & 27th meeting (1976) \\
\hline development & 7 & 3 \\
motor learning & 4 & 5 \\
perception-cognition & 6 & 2 \\
motor reaction & 7 & 3 \\
psychophysiological problem & 2 & 3 \\
personality & 10 & 1 \\
attitude, interest, consciousness & 6 & 3 \\
counseling, therapy, guidance & 4 & 3 \\
representation, image & 6 & 5 \\
others & 2 & 2 \\
\hline \multicolumn{1}{c}{ Total } & 54 & 30 \\
\hline
\end{tabular}

Comparing these numbers with the numbers of researches presented during the preceding two years (1973-1974), the following trends were observed:

(1) The number of the experimental researches increased. This trend could be partly attributed to the development of experimental apparatus.

(2) The number of researches on attitude and interest for the physical activities also increased.

(3) The number of researches on personality decreased remarkably.

(4) The practical researches were of a small number in almost all research areas.

At the symposium, held at National Covention of Japanese Society of Physical Education, the common topics were discussed. The theme of the symposium was a topic taken as the most interest in each year.

Sportsman's personality, motor learning and sports therapy were discussed at the sympo- 
sia so far. Then, at the latest symposia the following discussions were carried out;

1) 26th meeting (1975)

Main theme : Attitude formation toward the physical activities.

1. A. Kataoka (Tsukuba Univ.) : Social psychological study on attitude formation toward the physical activities.

2. H. Hyodo (Ehime Uuiv.) : Developmental analysis on likes and dislikes toward the physical activities.

3. G. Ishii (Chukyo Women's Univ.) : Relationship between attitude toward the winning or loosing and personality.

2) 27th meeting (1976)

Main theme : Study on the interest toward the physical activities.

1. M. Sakumoto (Fukuoka Women's Univ.) : A study on factor of dislikes toward the physical activities from the view point of an index of determination and the behavior tendency.

2. T. Sugihara (Tsukuba Univ.) : The means of the interest and the features of the interest in adolescence.

3. K. Choshi (Hiroshima Univ.) : The stratum structure of interest-the interest toward the physical activities and sports in a full-fledged member of society-.

The papers published in Japanese Journal of Physical Education in 1975-1976, which were originally written in Japanese with English summary, were as follows:

1. K. Takano, Body Reaction Times to Eight Different Directions in the Ego-Centric Space, J.J.P.E. Vol. 19, No. 6, 1975 (in English).

2. M. Tokunaga and K. Hashimoto, The Relationship between the Experience in Physical Activity and the Growth and Development-The Case for Senior High School Athletes-, R.J.P.E. Vol. 20, No. 2, 1975.

3. H. Yamada and K. Terada, Studies on Timing Control--The Influence of Colored Condition on the Timing Action-, R.J.P.E. Vol. 20, No. 3, 1975.

4. M. Okano and T. Niwa, A Developmental Study of the Synchronization of Rhythmic Pattern in Infants, R.J.P.E. Vol. 20, No. 4, 1976.

5. M. Kinjo and Y. Oshiro, A Study on the Appreciation of the Dance by Factor Analytic Approach, J.J.P.E. Vol. 21, No. 2, 1976.

National Convention of the Japanese Society of Sport Psychology, which is held annually, was instituted at 1974 and affiliated to the International Society of Sport Psychology. This society was expected to develop the sport psychology as a science. The latest theme of symposium was "a relationship between competitive sports and psychology." And the following papers were presented at this symposium.

1. K. Takano and M. Arai, The Personality Characteristics of Physical Education Major Student and Members of National Sport Teams from the View Point of Allport-Vernon Value Test, J.S.S.P. Vol. 2, No. 1, 1975.

2. A. Fujita and others, A Study of Training Effect upon Predictive Body Reaction, J.S.S.P. Vol. 2, No. 1, 1975. 